\title{
BEM-ESTAR ANIMAL E ENRIQUECIMENTO AMBIENTAL NA CRIAÇÃO DOMÉSTICA E ORNAMENTAL DE GANSOS E MARRECOS
}

\section{ARTIGO ORIGINAL}

FREITAS, Luiza Isaia de ${ }^{1}$

FREITAS, Luiza Isaia de. Bem-estar animal e enriquecimento ambiental na criação doméstica e ornamental de gansos e marrecos. Revista Científica Multidisciplinar Núcleo do Conhecimento. Ano 06, Ed. 01, Vol. 05, pp. 107-125. Janeiro de 2021. ISSN: 2448-0959, Link de acesso: https://www.nucleodoconhecimento.com.br/veterinaria/criacao-domestica

\section{RESUMO}

O conceito de bem estar animal vem sendo amplamente estudado e discutido nos últimos anos. Este trata-se de uma ciência, que busca uma melhora na qualidade de vida dos animais, garantindo que estes tenham o direito as suas 5 liberdades básicas respeitadas. As práticas de bem-estar animal buscam que os animais expressem seu comportamento natural, mesmo quando estes estão em cativeiro, assegurando sua saúde física e psicológica. Tais técnicas auxiliam na adaptação do animal ao ambiente, principalmente em animais cativos e em criações. Existe uma relação direta entre a implementação das práticas de bem estar animal e a capacidade de esses adaptar-se e ter uma boa qualidade de vida no meio em que foi inserido. O crescente aumento de criações de aves de forma ornamental e como pets, revelou a necessidade de estudar e assegurar as práticas de bem-estar na criação destes animais. Uma das técnicas utilizadas a fim de garantir o bem-estar animal é a implementação dos diferentes tipos de enriquecimentos ambientais. $O$ enriquecimento ambiental busca por meio de diferentes técnicas e materiais proporcionar ambientes mais atrativos e estimulantes aos animais, permitindo que haja interação entre os animais e animal-ambiente, possibilitando que este usufrua e explore o ambiente,

\footnotetext{
${ }^{1}$ Graduanda em Medicina Veterinária.
} 
otimizando os espaços disponíveis, oportunizando o desenvolvimento de comportamentos e habilidades naturais da espécie, diminuindo o estresse causado pela limitação do espaço e ausência de estímulos. O objetivo deste trabalho foi relacionar o bem-estar animal na implementação do enriquecimento ambiental em duas criações de gansos e marrecos, uma com fins ornamentais e outra doméstica, aves sendo criadas como pets. Em específico descrever a criação, relatar a implementação de três tipos de enriquecimento ambiental: alimentar, físico e social, e resposta das aves após a implementação desta técnica de promoção de bem-estar animal. Os resultados da implementação do enriquecimento ambiental alimentar, físico e social, para a melhora do bem estar das aves, foi verificado nas duas criações, obtendo resultado positivo. Houve melhora no comportamento dos animais, sendo este mais próximo do natural em ambos os grupos, atestando melhora na qualidade de vida e proporcionando bem-estar físico e psicológico às aves.

Palavras-Chave: Bem- estar animal, criação, enriquecimento ambiental, gansos, marrecos.

\section{INTRODUÇÃO}

O conceito de Bem-estar animal pode ser compreendido de maneiras diferentes entre as pessoas, ele está inteiramente ligado com a qualidade de vida do animal.

O tema já é bastante utilizado em animais de companhia, atualmente há discussões a respeito na área de produção animal (BENETTON, 2017; ALVES et al., 2007; CARVALHO et al, 2017). Na produção animal, os consumidores têm buscado adquirir produtos de locais onde há práticas de bem-estar animal, aumentando a preocupação com o tema.

Os animais são seres sencientes, são capazes de sentir emoções como felicidade e medo, sendo assim, garantir o bem-estar em sua criação é essencial, a fim de dar uma melhor qualidade de vida aos animais e livrá-los de qualquer tipo de sofrimento. 
Em criações conservacionistas "ex situ" há estudos das práticas de bem-estar animal em diferentes espécies. Uma das maneiras de garantir o bem estar destes animais é através do enriquecimento ambiental.

O enriquecimento ambiental pode ser físico, sensorial, alimentar, social ou cognitivo. Em aves, é comum a implementação destes enriquecimentos, em aves aquáticas é possível fornecer enriquecimento ambiental físico, sensorial, alimentar e social facilmente.

Neste estudo foram introduzidos em duas criações de gansos e marrecos, uma com fins ornamentais/comerciais e outra como animais pet, diferentes tipos de enriquecimentos ambientais, a fim de melhorar seu bem-estar e qualidade de vida.

Sendo assim, descreveremos como o enriquecimento foi implementado no ambiente dos animais e o resultado destes na melhora do comportamento e consequente bemestar das aves.

\section{BEM-ESTAR ANIMAL E ENRIQUECIMENTO AMBIENTAL}

\subsection{O BEM-ESTAR ANIMAL}

O termo Bem-estar animal foi citado pela primeira vez em 1965 na Inglaterra, pelo então comitê Brammel, um grupo denominado pelo Ministério da Agricultura Inglês. Desde então, seu conceito vem sendo ampliado e estudado, tornando-o uma ciência que diz respeito à qualidade de vida dos animais, avaliando-o em vários aspectos, como saúde, condição física e psicológica e se este tem a possibilidade de expressar o comportamento natural de sua espécie (BROOM e MOLENTO, 2004).

As práticas de bem-estar permitem que haja condições de um animal se adaptar ao ambiente, como por exemplo ao cativeiro e criações.

Há uma relação direta entre a implementação das práticas de bem estar animal e a capacidade de esse adaptar-se e ter uma boa qualidade de vida no meio em que foi inserido. 
O conceito que norteia as práticas do Bem-estar animal é o das cinco liberdades. Este foi criado pelo Conselho do Bem-Estar de Animais de Produção do Reino Unido (Farm Animal Welfare Council - FAWAC).

\subsubsection{AS CINCO LIBERDADES}

As cinco liberdades são conhecidas internacionalmente, elas representam uma forma de reconhecer, determinar e garantir os direitos básicos dos animais.

Segundo a Farm Animal Welfare Council, as cinco liberdades são definidas como:

1) Livres de fome e sede - Deve-se garantir o acesso ilimitado à água de boa qualidade e uma alimentação balanceada, a fim de suprir as necessidades fisiológicas e manter o animal saudável;

2) Livres de desconforto - Os animais devem possuir um ambiente apropriado, que seja confortável e seguro, que atenda suas necessidades de atividades e descanso;

3) Livres de dor, ferimentos e doenças - Os animais devem ter acesso a serviços veterinários, tanto preventivos, tanto de tratamento, de maneira que proporcione um diagnóstico e tratamento rápidos em casos de enfermidades;

4) Livres para expressar comportamento natural - Com o ambiente adequado, com espaço suficiente, práticas de socialização, como a companhia de animais da mesma espécie, afim do animal apresentar características de seu comportamento natural.

5) Livres de medos e angústias - Garantir condições e tratamentos que evitam o sofrimento, como boas práticas de manejo, proteção a predadores e separação de animais que possam gerar conflitos.

\subsection{BEM-ESTAR ANIMAL E O ENRIQUECIMENTO AMBIENTAL}

As pesquisas realizadas na área de bem-estar são a base para a definição de leis, acordos e demais iniciativas legais, a fim de garantir que sejam cumpridas e 
respeitadas as liberdades e direitos dos animais, assegurando sua saúde em todos os aspectos.

É comprovado em vários estudos que, animais criados em condições que consigam expressar seus comportamentos naturais, com práticas de bem-estar são mais eficientes de maneira produtiva, ou seja, além das práticas de bem-estar serem benéficas aos animais, os produtores que as aplicam em suas criações também são favorecidos, uma vez que, também, os consumidores têm buscado produtos com maior qualidade e com garantia de uma criação ética (SANS et al, 2014; SILVA et al, 2010; ZAGO, 2015).

Com a evolução da relação entre o homem e os animais, aumentando a proximidade e o convívio, o bem-estar animal vem sendo mais assegurado. Animais que antigamente eram utilizados para a proteção ou produção vem sendo criados na forma de pets.

Com as aves não foi diferente. A criação de aves de forma ornamental e como pet aumentou consideravelmente nos últimos anos, trazendo à tona as necessidades de bem-estar destes animais (CAMPOS, 2000).

Uma das maneiras de garantir o bem-estar animal é o enriquecimento ambiental. Basicamente podemos definir o enriquecimento ambiental (EA) como um princípio de manejo com fins de aprimorar a qualidade de vida dos animais cativos, sua condição de vida e seu bem-estar (CONCEA - ORIENTAÇÃO TÉCNICA № 12).

A implementação do EA busca por meio de diferentes técnicas e materiais proporcionar ambientes estimulantes aos animais, tornando o meio mais complexo, atrativo, facilitando a interação ambiente-animal, estimulando o psicológico e fisiológico dos animais, promovendo habilidades e comportamentos apropriadas à espécie, diminuindo o estresse causado pela limitação do espaço e ausência de estímulos (FREITAS et al, 2015)

O EA oferece melhorias na condição física e mental dos animais, aumentando a docilidade destes quando manejados, diminuindo a apresentação de distúrbios 
comportamentais, intervenções clínicas, mortalidade e consequentemente melhora a qualidade de vida e longevidade do animal (GREEN e MELLOR, 2011).

Estudos e relatos de caso, principalmente na área de conservação e criação de animais "ex situ" demonstram que o enriquecimento ambiental proporciona aos animais cativos a interação com o ambiente, de forma que, estes exibam comportamentos condizentes com os apresentados na natureza, usufruindo do meio, com possibilidades de explorar e otimizar o espaço, respeitando as características das espécies e melhorando as condições de vida (CAMPOS et al, 2017; JACINTO et al, 2010).

Através do enriquecimento ambiental é possível simular situações e interações com o ambiente semelhantes aos que o animal encontraria naturalmente, evitando o estresse e comportamentos anormais, estereotipados e repetitivos, comuns de acontecerem quando $O$ animal não possui estímulos o suficiente no recinto e fica entediado (CONCEA - ORIENTAÇÃO TÉCNICA № 12).

Em zoológicos e unidades conservacionistas o enriquecimento ambiental é indispensável, auxiliando na reabilitação dos animais, podendo tornar possível a reintrodução de alguns espécimes na natureza (DIAS et al, 2010; FERREIRA, 2020; JACINTO et al, 2010).

\subsection{IMPLEMENTAÇÃO DOS DIFERENTES TIPOS DE ENRIQUECIMENTO AMBIENTAL E O BEM-ESTAR ANIMAL}

$\mathrm{Na}$ implementação do enriquecimento ambiental são utilizadas diferentes técnicas, estas devem ser adequadas à espécie do animal a fim de garantir a segurança e uma boa variedade de experiências ao animal. Para isto, é indispensável conhecer o comportamento do animal quando está em vida livre e determinar quais destes comportamentos são importantes para sua sobrevivência e ocupam sua rotina e devem ser implementados em sua vida em cativeiro (OIE, 2019).

Existem diferentes tipos de enriquecimento ambiental que podem ser fornecidos. 
Basicamente, podemos dividir o EA em cinco tipos, este pode se dar por implementação de estruturas físicas (EA Físico), explorando os sentidos do animal (EA sensorial), interação segura e pacífica com animais da mesma espécie ou de espécies que este conviveria em conjunto na natureza (EA social), promover variação na alimentação dos animais (EA alimentar), ou ainda o EA cognitivo, que estimula a capacidade intelectual do animal (SILVA e MACÊDO, 2013).

Em aves os tipos de enriquecimento ambiental de mais fácil implementação e mais utilizados são o físico, alimentar e social.

Não basta apenas implementarmos o EA, é preciso nos certificarmos se o animal está realmente no estado de bem estar animal, para isto, podemos averiguar suas reações e comportamentos, se estes são condizentes com os naturais, se mantêm suas interações sociais, estáveis, sem apresentar comportamento agressivo ou comportamentos anormais, se apresentam bom desenvolvimento, temperatura corpórea normal, boa condição corpórea, balanço fisiológico e homeostase (GREEN e MELLOR, 2011).

Lembrando que o bem-estar não pode ser considerado um estado permanente, pois está sempre necessitando de adaptação conforme o período da vida do animal, tendo conceitos mutáveis durante a vida do animal.

Todos os materiais utilizados no enriquecimento ambiental devem ser atóxicos, não devem facilitar a fuga e devem ser seguros para os animais, sendo adequados ao tamanho do recinto, além disso, devem proporcionar aos animais a opção de escolha de interagir ou não com o enriquecimento oferecido (SILVA e MACÊDO, 2013).

$\mathrm{Na}$ criação de aves aquáticas, como patos, marrecos e gansos, o enriquecimento ambiental é indispensável, seja em uma criação doméstica ou ornamental. 


\section{CRIAÇÃO DE GANSOS E MARRECOS}

Gansos e marrecos são aves de hábitos aquáticos, pertencentes à família dos Anatídeos, Ordem Anseriformes. São aves rústicas, de fácil manejo e criação, se adequam facilmente em diferentes ambientes (SIGRIST, 2009).

Na natureza vivem em bandos, algumas espécies realizam migrações em busca de maior fartura de alimento e de melhores condições para sua reprodução.

Em criações, essas aves se habituam facilmente a rotinas de manejo e cuidados, reagindo bem ao contato com o ser humano (ALVES, 2019).

Essas aves possuem adaptações ao nado, como a existência de membranas entre os dedos dos pés e a secreção de substância oleosa impermeabilizante pela glândula uropigiana (localizada no final do dorso próxima a cauda), tal secreção, as aves espalham pelas penas com a ajuda do bico e essa impede que as aves se encharquem ao nadar (ALMEIDA, 2016).

Gansos e marrecos são aves que quando criadas em contato direto ao dono apresentam comportamento dócil. A expectativa de vida de ambos é superior a 15 anos (ALVES, 2019).

Os marrecos atingem a maturidade sexual a partir dos 6 meses de idade, já os gansos a partir dos 9 meses. Sendo a partir daí consideradas aves adultas.

Uma das maiores diferenças entre gansos e marrecos é o desapego dos marrecos perante os ovos e filhotes em oposto ao cuidado extremo dos gansos com os mesmos (MATHIAS, 2019; ALVES, 2019).

Gansas geralmente chocam logo após a postura (em média de 14 ovos por ciclo) e criam seus filhotes junto ao bando, já os marrecos a criação necessita de chocadeira ou outra ave para a choca, e um berçário para os filhotes na fase inicial (MATHIAS e SILVA, 2018). 
Em criações comerciais são comercializados sua carne, plumas, ovos, filhotes, matrizes, inclusive os rejeitos, como a venda das fezes para a elaboração de adubos ou insumos para a piscicultura (em contato com a água, as fezes dos marrecos e gansos possibilitam a formação de micro-organismos que são consumidos pelos peixes) (GONÇALVES, 2020).

Gansos também são criados com fins de proteção, são aves que tendem a defender o seu território de estranhos, sendo excelentes guardiões.

Atualmente, gansos e marrecos, vem sendo criados como pet e aves ornamentais, aumentando sua proximidade e relação com os humanos (FIORIN, 2020).

\subsection{MANEJO E ALIMENTAÇÃO}

A alimentação básica de ambas as espécies é capim, legumes, frutas, grãos, pequenos invertebrados, minhocas, ervas, caracóis e nas criações também é fornecida ração comercial, conforme a idade. Através do bico, as aves filtram a água e a lama obtendo matéria vegetal, insetos e larvas para a alimentação (SIGRIST, 2009).

Além da alimentação devem haver bebedouros com água limpa, é importante que os bebedouros não sejam os mesmos locais onde as aves se banham (GONÇALVES, 2020).

Os comedouros podem ser simples, e devem permitir que todas as aves tenham acesso ao alimento simultaneamente.

Assim como em frangos de corte, a criação pode ser dividida em fases, sendo estas: inicial, crescimento e a fase adulta (ou de engorda dependendo do fim da criação) (MATHIAS e SILVA, 2013).

A alimentação sofre modificações conforme o animal vai crescendo. $\mathrm{Na}$ fase inicial deve ser fornecida ração comercial, farelada, como a oferecida a pintos de corte, até os 21 dias de idade da ave. 
Após inicia-se a fase de crescimento, onde o tamanho do farelo da ração pode ficar maior, podendo ser oferecida ração peletizada e dar início a introdução ao pastejo e de outros alimentos a ave.

As aves adultas também devem receber ração, a ração comercial própria para aves como gansos e marrecos é difícil de encontrar, sendo então oferecida a ração comercial de postura ou a mistura de milho quebrado (ou farelado) e concentrado, a fim de atender todas as necessidades nutricionais da ave sem gerar a engorda (ALVES, 2019).

O fornecimento de ração de postura é de suma importância durante o ciclo reprodutivo, uma vez que as fêmeas produzem um alto número de ovos no ciclo e necessitam de níveis de garantias de vitaminas e minerais de forma semelhante a galinhas em postura.

Conforme Gonçalves (2020), durante a fase inicial os filhotes devem ter acesso a local aquecido, geralmente se faz uso de campânulas para o aquecimento das aves nesta fase. Além disso, deve ser fornecido abrigo a influências externas, acesso livre a água e alimento em forma de farelo.

Após os primeiros 7 dias os filhotes podem ter acesso a áreas externas, onde irão se habituar ao clima natural.

Completados 15 dias os filhotes de marrecos já podem ter acesso a locais com água para banhar-se, com profundidades inferiores à sua altura para evitar acidentes, enquanto aos gansos o acesso deve se dar após os 40 dias (MATHIAS e SILVA, 2018).

$\mathrm{Na}$ fase de crescimento já é possível oferecer ração comercial peletizada as aves, onde há menos perdas devido aos gansos e marrecos se alimentarem e logo tomarem água, desta forma, a ração peletizada oferece um maior rendimento, pois há menos desperdício de alimento pelas aves e menor poluição das fontes de água com o farelo de alimento. Durante esta fase é possível introduzir diferentes alimentos a ave, e acostumá-las ao manejo do criatório (MATHIAS e SILVA, 2013). 


\subsection{ESTRUTURAS PARA A CRIAÇÃO}

$\mathrm{Na}$ criação de aves como gansos e marrecos adultos não há necessidade de muita estrutura como na criação de frangos, basicamente deve ser fornecido uma área coberta para que as aves possam se abrigar de intempéries e abrigar os comedouros (MATHIAS, 2019).

É de suma importância que os comedouros fiquem em local coberto, pois a ração quando úmida e/ou molhada sofre fermentação, podendo a ave que ingerir ir a óbito.

Uma outra estrutura comum a ser oferecida a essas aves a fim de enriquecer o ambiente é a instalação de fontes de água para banhos. Estas devem ser limpas frequentemente a fim de evitar o surgimento multiplicação de algas, como as conhecidas algas verdes ou cianofíceas, as quais produzem toxinas que, quando ingeridas, podem ocasionar intoxicações graves e óbito (FREITAS, 2020), além do surgimento de lodo, material propenso a multiplicação do Clostridium botulinum, que pode levar as aves a severas intoxicações e a morte por Botulismo, principalmente nas épocas secas, as aves ao filtrarem a água com lodo, ingerem a toxina produzida pela bactéria (OLATE e LATORRE, 2008).

O fornecimento de local adequado para que as estas aves pratiquem o nado é essencial. Em criações onde não há este tipo de enriquecimento, as aves em crescimento apresentam maior propensão a desenvolverem problemas de desenvolvimento ósseos e articulares, principalmente quando em conjunto com a má nutrição (ARNAUT, 2006).

O acesso aos locais de banho deve ser livre a todas as aves, permitindo que estas possam entrar e sair facilmente.

Em criações comerciais, a área disponível por ave é relativamente pequena (cerca de $1,5 \mathrm{~m}^{2}$ por marreco), sendo nas criações ornamentais e em algumas domésticas que geralmente, estas possuem mais espaço disponível no ambiente para apresentarem o comportamento natural da espécie (GONÇALVES, 2020). 


\subsection{RAÇAS E INVESTIMENTO INICIAL DA CRIAÇÃO}

As raças que se destacam com maior número de criações no Brasil são, entre os Gansos a criação dos chamados "sinaleiros" (grasnado forte e excelentes defensores do ambiente), das raças: Chinês-branco e Chinês-pardo, Africano, Embden, Toulouse e o ganso comum (caipira), e entre os marrecos as raças: Pequim, Rouen, Pato-real e Corredor indiano (OLIVEIRA, 2019).

A proporção entre machos e fêmeas na criação se dá, na criação de gansos, de um macho para duas fêmeas, e em marrecos de um macho para até 6 fêmeas.

O investimento inicial da criação é baixo, sendo basicamente composto pelo valor da compra das matrizes (de 100 a 300 reais dependendo da raça) e da implementação de cercas (60 a $90 \mathrm{~cm}$ de altura são suficientes) e dos abrigos cobertos (MATHIAS e SILVA, 2013).

\subsection{SUSCETIBILIDADE A DOENÇAS}

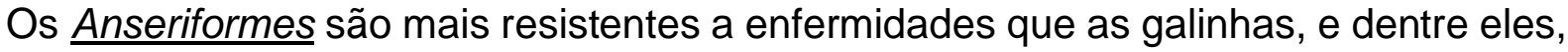
os gansos e marrecos são mais resistentes que os patos (ALMEIDA, 2016).

Essas aves apresentam maior susceptibilidade a patógenos durante as fases iniciais e de crescimento, devendo os cuidados serem mais intensos durante a juventude (OLIVEIRA, 2019).

Segundo Almeida (2016), há poucas pesquisas referentes às doenças em que essa ordem é mais propensa, o país onde há maior produção literária e pesquisas referentes é a China, que abriga a maior produção mundial desse tipo de ave.

No Brasil, país considerado livre da maioria dos patógenos causadores de doenças aviárias, geralmente as aves sofrem intoxicações (como botulismo e ingestão de toxinas produzidas por algas, por exemplo) do que a contração propriamente dita de uma doença. 
Segundo o Programa Nacional de Sanidade Avícola, a vacinação, como da Influenza Aviária e Micoplasmose, é proibida no território nacional.

$\mathrm{Na}$ Europa há casos recentes de acometimento dessas aves pela influenza (gripe) aviária, levando as aves ao sacrifício obrigatório (REUTERS, 2020).

\section{MATERIAIS E MÉTODOS}

A implementação do enriquecimento ambiental e seus resultados foi realizada em duas criações de aves aquáticas, uma com propósito ornamental/comercial, onde eram vendidos ovos, filhotes e matrizes, e outra criação com fins domésticos, com aves criadas como pet. Ambas as criações eram compostas por gansos e marrecos.

A criação doméstica (criação A), as aves eram criadas como pet, era composta por 7 animais, entre fêmeas e machos, destes 4 marrecos ( 3 marrecos de Pequim e a Marreco Rouen) e 2 gansos (1 Africano e 1 Sinaleiro Chinês), os quais conviviam no mesmo recinto, de aproximadamente $60 \mathrm{~m}^{2}$.

A outra criação, criação $B$, era maior, também composta por marrecos e gansos, formando um grupo de 19 animais, entre fêmeas e machos, sendo: 7 gansos Africanos, 2 Sinaleiros Chineses, 9 marrecos de Pequim e 2 Marrecos Rouen, instalados em uma área de aproximadamente $660 \mathrm{~m}^{2}$.

Para a implementação do enriquecimento ambiental nas criações objeto deste trabalho foram utilizados diferentes materiais e técnicas, a fim de promover enriquecimento físico, alimentar e social conforme o espaço disponível e o tipo de manejo, que era diferente entre as duas criações.

\subsection{ENRIQUECIMENTO SOCIAL}

O enriquecimento social foi forma semelhante em ambas as criações. Os animais, após atingirem a fase adulta, foram colocados no mesmo ambiente. 
Primeiramente as aves passaram por uma fase de adaptação, eram separadas por tela plástica, em altura de $60 \mathrm{~cm}$, em malha de tamanho em que as aves não poderiam passar a cabeça ou o bico para o outro lado da cerca.

Após não apresentarem mais comportamento agressivo e serem amistosos entre eles, foram inseridos no mesmo recinto, onde formaram um único bando com hierarquia definida.

Desta maneira os gansos e marrecos interagiam entre si, de maneira semelhante a interação que ocorreria na natureza. Após o grupo estar coeso, recebiam bem os novos filhotes, sem que ocorressem disputas por alimento, água ou abrigo.

\subsection{ENRIQUECIMENTO FÍSICO}

O enriquecimento físico foi implantado de maneira diferente nos dois grupos, descreveremos separadamente o enriquecimento físico e alimentar nos grupos de criação A e B.

\subsubsection{ENRIQUECIMENTO FÍSICO NA CRIAÇÃO A}

Como o espaço para a criação era limitado, cerca de $10 \mathrm{~m}^{2}$ por ave, foram implementados diferentes tipos de chão, a fim de proporcionar às aves contato com diferentes texturas.

O ambiente era composto por: área de caixa de areia (cerca de $2 \mathrm{~m}^{2}$ ), área com terra (cerca de $2 \mathrm{~m}^{2}$ ) onde eventualmente eram transplantadas gramíneas, área com piso de concreto (cerca de $14 \mathrm{~m}^{2}$ ), área com pedras (cerca de $30 \mathrm{~m}^{2}$, semelhantes a britas, porém arredondadas) e área com cobertura com piso de lajotas (cerca de $10 \mathrm{~m}^{2}$ ) e área com cobertura com chão de serragem $\left(2 \mathrm{~m}^{2}\right)$. Os pisos eram higienizados diariamente.

Além dos pisos, foram colocados tonéis plásticos, cortados ao meio, com água para banho, com altura de coluna de água maior que a altura da ave, podendo esta nadar. 
Os tonéis eram limpos diariamente pela manhã e pela tarde, sendo lavados e tendo a água trocada, e caso necessário, eram lavados ao meio dia (se a água já estivesse suja).

Diariamente os tonéis eram trocados de lugar no ambiente, respeitando uma distância de 1 metro entre eles, sendo implantados 1 tonel para cada duas aves.

A quantidade de tonéis foi suficiente para não gerar conflitos e competição entre as aves.

Os tonéis foram colocados na área de brita, assim como casinhas plásticas (como as utilizadas para cães), com ninhos feitos de maravalha, onde as fêmeas utilizavam como ninhos para postura. Duas fêmeas escolheram o mesmo ninho, todavia o tamanho da casinha era suficiente para que ambas entrassem simultaneamente.

$\mathrm{Na}$ área de brita possuía uma árvore que oferecia sombra natural aos animais.

As aves durante o dia podiam explorar livremente os ambientes conforme sua livre escolha, podendo escolher entre os diferentes chãos e se queriam ficar à sombra ou ao sol.

\subsubsection{ENRIQUECIMENTO FÍSICO NA CRIAÇÃO B}

Na segunda criação, com fins ornamentais e comerciais, o espaço disponível era de aproximadamente $34 \mathrm{~m}^{2}$ por ave, desta forma a implementação do enriquecimento ambiental físico e alimentar foram diferentes dos da criação $A$.

O ambiente da criação era amplo, com diversos tipos de árvores e arbustos, chão com gramíneas e terra.

Havia predominância de áreas de sombreamento natural, com poucas áreas de sol devido a intensa cobertura da copa das árvores. Para o nado das aves foi construído um lago, de concreto, com profundidade maior que a altura das aves, com pelo menos $8 m^{2}$ de área, onde as aves entravam e saiam livremente. 
Devido ao modo de construção a limpeza do lago era dificultada, acumulando lodo ao fundo. Uma vez ao ano, na época de seca era possível secar o lago e retirar o lodo acumulado.

Em um dos cantos do recinto foi construído abrigo coberto, com cerca de $6 \mathrm{~m}^{2}$, com cobertura lateral, onde as gansas e algumas marrecas faziam a postura, as demais marrecas colocavam os ovos pelo ambiente sem utilizar os ninhos.

\subsection{ENRIQUECIMENTO ALIMENTAR}

\subsubsection{ENRIQUECIMENTO ALIMENTAR NA CRIAÇÃO A}

Devido a criação ser de caráter pet, o enriquecimento alimentar foi favorecido, devido a não preocupação com os custos da implementação deste na criação.

Diariamente era oferecida ração comercial para postura peletizada para as aves, os comedouros eram colocados durante o dia, preenchidos de ração (quantidade suficiente para todas as aves sem oferecer alimento em excesso), e à noite recolhidos, para evitar contato de vetores com os restos de alimento.

Em dias chuvosos os comedouros e bebedouros eram instalados nas áreas cobertas, podendo os animais terem livre acesso aos demais ambientes.

Além da ração, diariamente eram oferecidos legumes, verduras, frutas, gramíneas e pastagens. Era fornecida às aves de maneira aleatória: couve, espinafre, cenoura ralada ou filetada, talos e folhas de brócolis, folhas de repolho, beterraba cozida em pedaços, cascas de frutas, mamão, melancia, pedaços de manga, banana, grama cortada, pastagens da estação, tomates, etc.

A cada dia eram oferecidos diferentes alimentos, permitindo que os animais entrassem em contato com alimentos de diferentes formas, texturas e sabores, enriquecendo a alimentação e dando a oportunidade de as aves escolherem o alimento que queriam consumir. 


\subsubsection{ENRIQUECIMENTO ALIMENTAR NA CRIAÇÃO B}

A alimentação das aves da criação B se dava por milho em farelo misturado em concentrado de postura. Esta era oferecida pela manhã e ao entardecer.

Além da ração, à tarde, as aves tinham acesso a áreas com grama/pasto, podendo apresentar o comportamento de pastejo natural.

Eventualmente eram oferecidos legumes e verduras, como alface, couve, espinafre e tomate as aves, que eram plantados na horta do proprietário, além de grama e pastagens cortadas.

\section{RESULTADOS E DISCUSSÃO}

Em ambas as criações o enriquecimento social se deu de maneira semelhante, assim como os resultados obtidos. As aves, conviviam de maneira pacífica entre si, formando uma hierarquia com machos e fêmeas dominantes do bando, apresentando o comportamento de sociedade natural entre elas.

$\mathrm{Na}$ criação $\mathrm{A}$, havia apenas um macho de cada espécie, formando um bando único e unido, sem competição pelas fêmeas.

$\mathrm{Na}$ criação $\mathrm{B}$, haviam mais machos, tendo uma proporção próxima de um macho para cada fêmea, gerando uma competição natural pela cobertura das mesmas nos marrecos, e a formação natural de casais entre os gansos. Todavia tal competição pelo acasalamento não gerava conflitos entre as aves.

No enriquecimento físico, houve maior mudança de comportamento nas aves da criação $A$, onde pararam de apresentar comportamentos repetitivos.

As aves passavam diferentes partes do dia explorando o ambiente, banhando-se e limpando suas penas, interagindo entre si, eram atentas a qualquer modificação no meio. 
Além disso, como a criação era pet, as aves se aproximavam para interagir com os humanos, ganhando carinho e dormindo no colo das criadoras.

Nas aves da criação ornamental, devido ao amplo espaço disponível, houve pouca mudança no comportamento. Algumas aves se banhavam durante o dia, mas na maior parte do tempo percorriam o recinto em busca de alimento, como a caça a insetos.

No enriquecimento alimentar, o grupo pet recebia maior variedade de alimentos, além de serem estimulados a captar esses alimentos de diferentes maneiras, como pendurados ou escondidos entre as pedras, além de caçar insetos e minhocas. Já o grupo B podia expressar seu comportamento natural ao pastejar, caçar insetos no amplo recinto e receber eventualmente diferentes alimentos.

Em ambas as criações foi possível averiguar a melhora no bem-estar e qualidade de vida dos animais. As aves apresentavam desenvolvimento adequado, bom escore corporal, expressavam comportamentos naturais da espécie, interagiam socialmente entre eles, eram dóceis ao manejo (a criação A ainda mais devido a proximidade da relação com os criadores), suas temperaturas corporais estavam normais (averiguadas por amostragem na criação B) e estavam livre de doenças e parasitas.

$\mathrm{Na}$ criação $\mathrm{A}$, onde anterior a implementação dos enriquecimentos ambientais físico e alimentar os animais apresentavam eventualmente comportamentos repetitivos, estes foram normalizados após a implementação do EA.

\section{CONSIDERAÇÕES FINAIS}

Há um dever ético em se ter uma criação de animais ou manter animais em cativeiro. Devemos proporcionar-Ihes saúde física e psicológica, oferecendo ao animal a possibilidade de escolha, de exercitar suas reações perante do ambiente em que está inserido e apresentar o comportamento natural da sua espécie.

Desta maneira utilizamos o enriquecimento ambiental para proporcionar aos animais das duas criações diferentes tipos de interação com o seu ambiente, tornando-o o mais dinâmico e interativo possível, melhorando sua qualidade de vida. 
Nas duas criações, foram implementados diferentes materiais para o enriquecimento físico e alimentar, com base na área disponível no recinto e características do manejo de cada criação, a fim de garantir a melhora no bem-estar e qualidade de vida dos animais, respeitando sua liberdade de escolha.

Desta forma concluímos que em ambas as criações foi possível implementar o enriquecimento ambiental físico, alimentar e social. Através de diferentes ferramentas foi proporcionado nas duas criações melhor qualidade de vida e boas práticas de bem estar, havendo melhora no comportamento das aves, sem estas apresentaram mais comportamentos estereotipados e repetitivos, apresentando o comportamento natural da espécie e melhor relação e interação entre as aves e o meio.

\section{REFERÊNCIAS}

ALMEIDA, A. M. DE S.; Principais doenças em anseriformes; Programa de pós graduação em Ciência Animal da Escola de Veterinária e Zootecnia da Universidade Federal de Goiás; 2016; Disponível em: $<$ https://files.cercomp.ufg.br/weby/up/67/o/2013_Ana_Maria_2corrig.pdf>; Acesso em 20 de novembro de 2020.

ALVES, M.; Marreco é uma ave que exige poucos cuidados na criação; Agro 2.0; 2019; Disponível em:< https://agro20.com.br/marreco/> Acesso em 20 de novembro de 2020.

ALVES, S.P., SILVA, I.J.O., PIEDADE, S.M.S. Avaliação do bem-estar de aves poedeiras comerciais: efeitos do sistema de criação e do ambiente bioclimático sobre o desempenho das aves e a qualidade de ovos. Revista Brasileira de Zootecnia, Viçosa, v.36, n.5, set./out. 2007.

ARNAUT, L.S; Estudo radiográfico das afecções do sistema esquelético em aves. Dissertação de Mestrado em Clínica Cirúrgica Veterinária, Faculdade de Medicina Veterinária e Zootecnia, Universidade de São Paulo, São Paulo, SP. 121p. 2006. 
BENETTON, R. P. D. P; Bem-estar animal em poedeiras: Sistemas de produção e debicagem; Universidade Estadual Paulista "Júlio de Mesquita Filho", campus de Araçatuba, Trabalho de Conclusão de curso, 2017. Disponível em: < https://repositorio.unesp.br/bitstream/handle/11449/156820/000902457.pdf?sequenc $\mathrm{e}=1$ \&isAllowed $=\mathrm{y}>$ Acesso em 27 de novembro de 2020.

BROOM, D. M.; MOLENTO, C. F. M. Bem-estar animal: Conceito e questões relacionadas - Revisão. Archives of Veterinary Science, v. 9, n. 2, p. 1-11, 2004.

CAMPOS, J. C. D., et al; Estudo comportamental utilizando técnicas de enriquecimento ambiental para papagaios-do-mangue (Amazona amazonica) em reabilitação; IV Congresso de Ensino, Pesquisa e Extensão da UEG; v4, 2017.

CAMPOS, E. J. O; Comportamento das Aves. Revista Brasileira de Ciência Avícola. Campinas, v. 2 n. 2, 2000.

CARVALHO, L. C.; et al; Bem-estar na produção de galinhas poedeiras - Revisão de literatura; Revista Científica de Medicina Veterinária - ISSN 1679-7353 Ano XIV Número 28, Janeiro de 2017, Periódico Semestral; Disponível em:< http://faef.revista.inf.br/imagens_arquivos/arquivos_destaque/w9h0rwyRxbJgkyH_20 17-3-2-21-47-54.pdf> Acesso em 27 de novembro de 2020.

CONCEA; Orientação técnica $n^{\circ}$ 12; Disponível em: < https://www.ceua.ufv.br/wpcontent/uploads/2018/05/ORIENTACAO-TECNICA-N\%C2\%BA-12.pdf $>$; Acesso em 20 de novembro de 2020.

DIAS, E. S.; MARTINS, A. C.; PESSUTTI, C.; BARRELLA, W. Enriquecimento Ambiental no Recinto do Mutum-de-Penacho (Crax fasciolata) do Parque Zoológico Municipal "Quinzinho de Barros". Revista Eletrônica de Biologia. Sorocaba-SP, v.3, n.3, p.20-38, 2010.

FAWC (Farm Animal Welfare Council). Farm Animal Welfare in Great Britai: Past, Present and future. Disponível em: https://www.gov.uk/government/uploads/system/uploads/attachment_data/file/31929 
2/ Farm_Animal_Welfare_in_Great_Britain_-_Past_Present_and_Future.pdf. Acesso em 20 de novembro de 2020.

FERREIRA, G. C.; Enriquecimento ambiental aplicado ao bem-estar de Aratinga leucophthalma; Universidade Estadual Paulista; Araçatuba: [s. n], 2018; Disponível em:<

https://repositorio.unesp.br/bitstream/handle/11449/153849/ferreira_gc_me_araca_in t.pdf?sequence=3\&isAllowed=y>, Acesso em 20 de novembro de 2020.

FIORIN, A.; Apostar na criação de aves ornamentais virou negócio lucrativo; Diário da região; Dezembro de 2018; Disponível em:< https://www.diariodaregiao.com.br/_conteudo/2018/12/economia/agronegocio/11332 16-apostar-na-criacao-de-aves-ornamentais-virou-negocio-lucrativo.html> Acesso em 20 de novembro de 2020.

FREITAS, E.Y.G.; RIBEIRO, J.S.S.; OLIVEIRA, L.B.S.; FARIA, M.C.A.F.; MELO, M.I.V. Estudo comportamental e enriquecimento ambiental para araras Canindés (Ara Ararauna, Linnaeus, 1758) de um mantenedor de fauna silvestre; Anais da VI Conferência Internacional de Medicina Veterinária do Coletivo; Belo HorizonteMG, 2015.

FREITAS, L. I.; Intoxicação por algas de água doce em animais; Anais do I Congresso Brasileiro de Ciências Biológicas On-line; v. 1, s. 1; p. 1 a 191; Editora IME, Fortaleza - CE; 2020.

GONÇALVES, V.; Criação de marrecos - Guia completo passo a passo para ter a sua; Novo negócio; Disponível em: < https://novonegocio.com.br/criacoes/criacaode-marrecos/> Acesso em 20 de novembro de 2020.

GREEN T.C.; MELLOR, D.J. Extending ideas about animal welfare assessment to include 'quality of life' and related concepts. N. Z. Vet. J. 2011, 59, 316-324. Disponível em: http://www.tandfonline.com/doi/abs/10.1080/00480169.2011.610283. Acesso em 20 de novembro de 2020. 
JACINTO, J. J.; IZUTANI, T. Y.; LEIMIG, R. DE A.; Análise e eficácia do enriquecimento ambiental entre diferentes espécies de psitacídeos no foz Tropicana Parque das Aves, Foz do Iguaçu, Paraná, II CONFERÊNCIA BRASILEIRA DE ENRIQUECIMENTO AMBIENTAL (CBEA); outubro 2010; Disponível em:< https://www.academia.edu/34559793/AN\%C3\%81LISE_E_EFIC\%C3\%81CIA_DO_E NRIQUECIMENTO_AMBIENTAL_ENTRE_DIFERENTES_ESP\%C3\%89CIES_DE_P SITAC\%C3\%8DDEOS_NO_FOZ_TROPICANA_PARQUE_DAS_AVES_FOZ_DO_I GUA\%C3\%87U_PARAN\%C3\%81> Acesso em 27 de novembro de 2020.

MATHIAS, J.; SILVA, M. V. F.; Como criar marreco; Revista Globo Rural; 2013; Disponível em:<https://revistagloborural.globo.com/vida-na-fazenda/comocriar/noticia/2013/12/como-criar-marreco.html> Acesso em 27 de novembro de 2020.

MATHIAS, J.; SILVA, M. V. F.; Como criar ganso; Revista Globo Rural; 2018; Disponível em: $\quad<\quad$ https://revistagloborural-globocom.cdn.ampproject.org/v/s/revistagloborural.globo.com/amp/vida-na-fazenda/comocriar/noticia/2018/04/como-criar-ganso.html>; Acesso em 27 de novembro de 2020.

MATHIAS, J..; Como criar ganso; Revista Globo Rural; 2019; Disponível em: < https://revistagloborural.globo.com/vida-na-fazenda/como-

criar/noticia/2019/01/como-criar-ganso.html>; Acesso em 27 de novembro de 2020.

OIE (World Organisation for Animal Health). Terrestrial Animal Health Code, Volume 1. 2019; Disponível em: http://www.oie.int/index.php?id=169\&L=2\&htmfile=chapitre_aw_introduction.ht $\mathrm{m}$. Acesso em 20 de novembro de 2020.

OLATE, H. H., LATORRE,, D.F. M.; Botulismo en aves acuáticas silvestres. Tecnología Veterinaria, 14(3): 16- 21. 2008; Disponível em:<https://revistateoria.uchile.cl/index.php/RT/article/download/15917/16403> Acesso em 27 de novembro de 2020. 
OLIVEIRA, A.; Criação de gansos: principais raças, reprodução, alimentação e instalações; Cursos CPT; 2019; Disponível em: < https://www.cpt.com.br/artigos/criacao-de-gansos-principais-racas-reproducaoalimentacao-e-instalacoes>; Acesso em 20 de novembro de 2020.

PROGRAMA NACIONAL DE SANIDADE AVÍCOLA; Ministério da Agricultura, Pecuária e Abastecimento; PNSA; Portaria n 193 de 19 de setembro de 1994. Disponível em:<https://www.gov.br/agricultura/pt-br/assuntos/sanidade-animal-evegetal/saude-animal/programas-de-saude-animal/pnsa> Acesso em 27 de novembro de 2020.

REUTERS, M. D.; Com rápido avanço, gripe aviária preocupa indústria da UE; Revista Exame; Online; Publicado em 26 de novembro 2020; Disponível em:<https://exame.com/mundo/com-rapido-avanco-gripe-aviaria-preocupa-industriada-ue> Acesso em 28 de novembro de 2020.

SANS, E. C. O.; et al. O enriquecimento ambiental sobre o bem-estar de frangos de corte. Cienc. Rural, Santa Maria, v. 44, n. 10, p. 1867-1873, Oct. 2014.2 Disponível em: <http://www.scielo.br/scielo.php?script=sci_arttext\&pid=S0103-

$84782014001001867 \&$ lng=en\&nrm=iso>. Acesso em: 20 novembro 2020. https://doi.org/10.1590/0103-8478cr20120504.

SIGRIST, T. Avifauna Brasileira: The avis brasilis field guide to the birds of Brazil, 1ำ edição, São Paulo: Editora Avis Brasilis, 2009.

SILVA, T. G. G.; VIEIRA, L. N. G.; BARRELLA, W. Estudo preliminar de enriquecimento ambiental no recinto do Ramphastos toco (Tucano-toco). Revista Eletrônica de Biologia. Sorocaba-SP, v.3, n.3, p.93-104, 2010.

SILVA, A. T.; MACÊDO, M. E.; A importância do enriquecimento ambiental para o bem estar dos animais em zoológicos; Centro Universitário Metodista Izabela Hendrix - Campus Praça da Liberdade; 2013; Disponível em: 
https://www.metodista.br/revistas/revistas-

izabela/index.php/aic/article/download/501/426 Acesso em 20 de novembro de 2020.

ZAGO, C. H. F.; Enriquecimento Ambiental sobre 0 desempenho e comportamento de frangos de corte; Universidade Tecnológica Federal do Paraná;

Dois Vizinhos; 2015; Dissertação de Mestrado; Disponível em:< https://repositorio.utfpr.edu.br/jspui/bitstream/1/2324/2/DV_PPGZO_M_Zago\%2C\%2 0Cl\%C3\%A1udia\%20Helena\%20Ferreira_2015.pdf> Acesso em 20 de novembro de 2020.

Enviado: Dezembro, 2020.

Aprovado: Janeiro, 2021. 